\title{
Subsequent Pregnancy in Women with a History of Postpartum Psychosis
}

Richard G. Hersh, M.D.

Northwestern University, Chicago, Illinois

Follow this and additional works at: https://jdc.jefferson.edu/jeffjpsychiatry

Part of the Psychiatry Commons

Let us know how access to this document benefits you

\section{Recommended Citation}

Hersh, M.D., Richard G. (1991) "Subsequent Pregnancy in Women with a History of Postpartum

Psychosis," Jefferson Journal of Psychiatry. Vol. 9 : Iss. 1 , Article 8.

DOI: https://doi.org/10.29046/JJP.009.1.006

Available at: https://jdc.jefferson.edu/jeffjpsychiatry/vol9/iss1/8

This Article is brought to you for free and open access by the Jefferson Digital Commons. The Jefferson Digital Commons is a service of Thomas Jefferson University's Center for Teaching and Learning (CTL). The Commons is a showcase for Jefferson books and journals, peer-reviewed scholarly publications, unique historical collections from the University archives, and teaching tools. The Jefferson Digital Commons allows researchers and interested readers anywhere in the world to learn about and keep up to date with Jefferson scholarship. This article has been accepted for inclusion in Jefferson Journal of Psychiatry by an authorized administrator of the Jefferson Digital Commons. For more information, please contact: JeffersonDigitalCommons@jefferson.edu. 


\title{
Subsequent Pregnancy in Women with a History of Postpartum Psychosis
}

\author{
Richard G. Hersh, M.D.
}

\section{INTRODUCTION}

Postpartum psychosis stands out among the psychiatric syndromes associated with childbirth, notable for the variability of its symptom profile and the potential severity of its course, if unrecognized. Significant questions regarding nosology, etiology, prevention and treatment remain only partially answered (1). While controversy surrounds many of the critical issues regarding postpartum psychosis, including its definition, current epidemiologic data indicates severe, frequently psychotic episodes occur following 1-2 per 1,000 of all births (2). As diagnosis and treatment of puerperal conditions have evolved, clinicians now are frequently involved in assisting women with a history of postpartum psychosis with decision making about subsequent pregnancies. The purpose of this paper is to review the fundamental issues related to postpartum psychosis, examine the risk of subsequent episodes of psychiatric illness in postpartum and non-postpartum periods, and review three cases of women hospitalized with postpartum psychosis who went on to deliver a second child without incident, focusing on issues of prediction, prophylaxis and intervention.

\section{NOSOLOGY}

Postpartum psychoses do not appear in the American Psychiatric Association Diagnostic and Statistical Manual, third edition, revised (DSM III-R) as a specific disease entity. They are included as examples of "atypical psychosis," described as disorders with psychotic symptoms that "do not meet the criteria for any other non-organic psychotic disorder" (3).

Brockington et al. in Motherhood and Mental Illness (4) outline the debate between those who view puerperal psychosis as a distinct disorder, and those who see the disorders as essentially no different from similar psychiatric syndromes observed in patients in non-puerperal periods. This debate has been raging since puerperal psychoses were first described in the 19th century; Hamilton (5) describes the conflict as it took hold at the time of the development of the first Diagnostic and Statistical Manual in 1952. Hamilton has championed the view that postpartum psychoses are distinct disorders; he suggests that "psychiatry and obstetrics for the next quarter century (after 1952) have denied the unique qualities and syndromes that have been described earlier, and encouraged diagnosis and treatment of postpartum cases without reference to the act of parturition." Miller (1), in her review, concluded that even with recent studies which have attempted to systematically evaluate features of 
postpartum psychosis which might distinguish it from other psychotic disorders, puerperal psychoses continue to "closely resemble other psychoses, particularly those associated with major mood disorders." She endorsed further investigation of "theories that propose multifactorial causation," which, she concluded, might be most compatible with current data.

\section{EPIDEMIOLOGY}

Recent retrospective epidemiologic studies based on psychiatric admissions following childbirth have found rates of severe psychotic episodes following childbirth in order of $1-2$ per 1,000 births $(2,6)$. Kendell et al. concluded that the relative risk for psychiatric admission with or without psychotic illness was "extremely high" in the postpartum period. They found rates of admission six times the norm in the first month and almost four times the norm in the first three months postpartum, when compared with antepartum statistics. When evaluating statistics for admissions marked by psychosis, the relative risk rises to over twelve times expected in the first month and twenty-one times expected in the first three months postpartum.

Dean et al. (7) used retrospective data to evaluate symptom profiles of patients admitted within 90 days of delivery. They concluded that those with puerperal illness described as a major depressive disorder differed from non-puerperal controls because of more prominent symptoms of delusions, hallucinations, agitation, lability and disorientation. Meltzer and Kumar (8) reviewed 142 cases of mothers admitted to psychiatric hospitals within 12 months of hospitalization, finding a predominance of affective disorders, by diagnosis, in the population of almost $80 \%$. Brockington et al. (9) compared a group of women with puerperal psychoses with a group with non-puerperal psychotic illness; they reported more prominent manic symptoms, particularly confusion, which they concluded supports a link between puerperal psychosis and manic-depressive disease.

Davidson and Robertson's (10) follow-up study of postpartum illness provides information regarding long-term prognosis. They followed 82 patients over 23 years, assessing recurrence of illness which they defined as the presence of symptoms or behavior disturbance severe enough to warrant either hospitalization, of if adequately documented, outpatient treatment and medication. For those patients in whom puerperal psychosis was their first psychiatric illness, $51 \%$ experienced recurrent non-postpartum psychiatric illness and 38\% recurrent postpartum psychiatric illness by their report. They proposed a continuum based on initial diagnosis, with those diagnosed initially with schizophrenia most likely to experience recurrent illness, those with bipolar diagnosis somewhere in between, and those with unipolar depression least likely to have recurrent illness. Of those patients in their study who had further children, one of three pregnancies resulted in postpartum psychosis in the mother; there was a range from the unipolar depression category $(24 \%$ of pregnancies resulting in such episodes), bipolar disorder (22\%), and schizophrenia $(66 \%)$, indicating a variation in long-term prognosis based on both initial diagnosis and subsequent illness described. 


\section{ETIOLOGY}

Postpartum psychoses have been investigated with hypotheses of genetic, biologic and psychosocial etiologies since the syndrome was first described, but no single etiologic factor has yet been conclusively identified.

A series of investigations attempted to document an inherited predisposition to puerperal psychoses with unexpected results. Protheroe (11) studied rates of puerperal psychosis in first degree relatives of 98 patients with documented postpartum illness (a total of 386 pregnancies), and found rates no higher than that in the general population. Whalley (4) compared family histories of 17 puerperal psychotics and 20 bipolar patients again finding the same risk of puerperal psychosis in both populations. Reich and Winokur (12) came to similar conclusions and found no significant family loading for postpartum illness, but did examine data on families of bipolar patients, finding a very high proportion of relatives with postpartum psychiatric illness, pointing the way to consideration of a theory of bipolar diathesis combined with biologic and or psychosocial stressors of childbirth, as proffered by Miller (1).

Despite widespread speculation about puerperal hormonal shifts, no evidence for a clear link between hormone levels and psychotic symptoms has ever been established. Hamilton (5) suggested a link between progesterone levels and puerperal psychosis; more recently Mallett (13) et al. have considered estrogen level shifts as a precipitant, but no conclusive research has been done. Stewart et al. (14) recently looked at postpartum thyroid function in patients with puerperal psychosis, but found no significant differences in thyroid function or the presence of thyroid antibodies; again, despite attempts to link the disorder with endocrine changes, no association was confirmed. Riley and Watt (15) have found a link between hypercalcemia and puerperal psychosis in those women with no personal or family psychiatric history; the usefulness of this observation has not yet been established, but it does reflect a continued effort to explore organic etiologicies for this condition.

Investigation of psychosocial stressors and their connection with postpartum psychosis by Rendell et al. (16) yielded results indicating risk factors including having a first baby, unmarried status, and undergoing caesarian section, while twin births, perinatal death and maternal age were not found to be risk factors. McNeil's $(17,18,19)$ prospective study found no association between puerperal psychosis and life situation and/or the experience of pregnancy including variables such as social class, relatives support for the pregnancy, interpersonal difficulties and the woman's negative attitude toward the pregnancy. In fact, this study found that women going on to psychosis were likely to have fewer housing problems, fewer physical complaints secondary to pregnancy, to have done more preparation for the child during pregnancy and have a more positive attitude toward the pregnancy. Clearly psychosocial stressors play a complex and, as of yet not fully understood, role in the expression of postpartum psychotic illness.

\section{Case 1}

Ms. A, now forty-six years old was married and employed as a school teacher when she became pregnant and delivered her first child, a son, in January, 1969. The 
patient and her husband, both white, Jewish and college educated, had been married for three years prior to conceiving a child, which resulted in a miscarriage at ten weeks, one year before her full-term delivery. Both pregnancies had been planned; the patient and her husband, who were later divorced, were at that point, by her report, content in their relationship. They lived in close proximity to their families of origin, who had volunteered their support, financial and emotional, with the birth of their son.

Ms. A recalls being concerned during her pregnancy because of her previous miscarriage, describing herself as "worried all the time." She remained in the hospital following the delivery for one week, her recuperation complicated by her episiotomy as well as a minor postpartum infection which resolved with antibiotic treatment. Ms. A and her husband were at home with a hired live-in nurse for the second postpartum week; the nurse assumed responsibility for most of the infant care. Ms. A reports feeling during that week that she "couldn't do anything," but she and her husband planned to assume full care of the baby at postpartum week three, and the nurse was discharged. During this time, Ms. A reports feeling anxious. Soon thereafter she visited her obstetrician "in tears," who then referred her to a psychiatrist who treated her with amitriptyline for four weeks as an outpatient. Ms. A had no prior psychiatric history, nor was their any family psychiatric history, which caused her, she recalls, to be reluctant to initiate psychiatric treatment. Ms. A was hospitalized at week six postpartum with symptoms of suicidal ideation, helplessness, hopelessness and delusions, with a clinical picture meeting DSM III-R criteria for a major depression with psychotic features.

Five and a half months postpartum Ms. A while still hospitalized and, by her report, responding minimally to pharmacotherapy, walked off the hospital grounds while on an activity and went to O'Hare Airport, planning to lie down on a runway and let a plane run her over. She then received the first of six treatments in a course of electroconvulsive therapy. She reported "immediate" resolution of her symptoms of depression, and following the course of treatment was released from the hospital with outpatient follow-up which included infrequent supportive contact with her treating psychiatrist, but no medication or sustained individual psychotherapy.

Ms. A's third pregnancy, two years later, was again planned. Her pregnancy was uneventful; she continued to have contact with her psychiatrist who educated her and her husband about symptoms of psychosis and depression, but received no prophylactic medication. She had a full-term vaginal delivery; her psychiatrist visited her in the hospital in the immediate postpartum period. She reported no episodes of anxiety, depression or psychotic thinking in the period following this second delivery.

Case 2

Ms. C was thirty years old, married for three years and employed as a management consultant at the time of her first pregnancy in 1987-88. Ms. C and her husband, both white, Catholic and college educated, had begun dating in high school 
and knew each other for ten years before their marriage. At the time of their marriage, the patient's husband was employed as a pharmacist and was earning an advanced business degree at night.

Patient and her husband decided to have a child and almost immediately patient became pregnant, much to her surprise. While they were financially comfortable, patient had just begun a particularly taxing long-term project at work felt the pregnancy might effect her work performance. Patient and her husband were surrounded by family members eager to be of help with their new baby; however, they planned to act as primary caretakers, and Ms. C had planned to take off two months from work to stay at home with her baby.

Ms. C reported at the time of her pregnancy she was still in mourning following her mother's death from breast cancer the previous year. Ms. C remained close to her father, however, and was in contact with him daily. Ms. C reported that neither she nor any immediate family member had a history of psychiatric illness, but she did describe her father's extended family as being "filled with alcohol abusers."

Ms. C delivered at eight months, following a premature rupture of membranes; her postpartum course was complicated by a transient flu-like episode on day number three following delivery for which she received antibiotics. Three months before becoming pregnant, Ms. C had been diagnosed with ulcerative colitis; she received a one-month course of cortisone enemas, but had no recurrence during her pregnancy or in the postpartum period.

During her first week at home with the baby, the patient noted a marked increase in anxiety and gradually over the next seven weeks she became, by report, increasingly bizarre with marked paranoid ideation, sleeplessness, racing thoughts, religious preoccupations, with symptoms consistent with a severe manic episode with psychotic features.

The patient was hospitalized twelve days during which she rapidly responded to pharmacologic intervention with high potency neuroleptic medication. She was discharged from the hospital on this medication following resolution of the aforementioned symptoms. The patient continued in supportive, weekly psychotherapy treatment for the next six months, as her medication was tapered.

One year later Ms. C became pregnant again. This was not a planned pregnancy, and it was complicated by a flaring of her colitis, which was then controlled with steroids. During this period, Ms. C contacted her psychiatrist, with whom she had terminated, to discuss the risk of another episode of postpartum psychosis. She was advised to monitor her sleeping pattern, in the immediate postpartum period, and to remain vigilant about signs of hyperactivity, pressured speech or paranoia. She received no prophylactic medication, but was offered low dose, short acting benzodiazepines in the event that her sleep-wake pattern was markedly disturbed. Patient had a full-term vaginal delivery and the postpartum period was without incident. She and her husband remained in contact by telephone with her psychiatrist, but no additional office visits were arranged. 


\section{Case 3}

Mrs. E was twenty-eight years old when she gave birth to her first child, a son, following seven years of marriage. The patient had had a miscarriage the year prior to her first successful pregnancy and delivery, but her son was born at term following an uncomplicated pregnancy, although delivery was marred by a vaginal tear which required medical follow-up.

Mrs. E and her husband, both white and Protestant, met while in college and married at age 21 upon graduation. They planned their pregnancies; while they were both employed, she as an administrative assistant at a large food processing business and he as a salesman, and financially secure, they both planned to return to work following their son's birth, he immediately, and she after a six week maternity leave.

Mrs. E was raised in a close knit family; she enlisted her parents' support with care of her infant son. Mrs. E had no prior history of psychiatric treatment, but she reported difficulty in adjusting to adolescence and was taken to the family doctor following a suicide gesture, by overdose, at age 14. Neither the patient, nor any of her family, had a history of psychiatric treatment or hospitalization, however.

Six weeks postpartum, Mrs. E returned to her job as an administrative assistant. She recalls feeling guilty about leaving her infant son at home, in particular when he had transient episodes of allergy to formula as well as projectile vomiting. She remained at work until sixteen weeks postpartum when she gradually became anxious, agitated, tearful; she remained at home for four days before being hospitalized. The patient's course included three extensive inpatient hospitalizations over the next two years; her symptoms included auditory hallucinations, as well as vegetative signs of depression with marked suicidal ideation. She received a diagnosis of major depression with psychotic features. Treatment modalities used during these hospitalizations included use of neuroleptics, antidepressants, and lithium. During this patient's third hospitalization, she received a course of fifteen treatments with electroconvulsive therapy, as pharmacologic interventions were not deemed efficacious. Mrs. E was eventually stabilized and discharged on neuroleptics and benzodiazepines; she continued to see her psychiatrist weekly for medication management, symptom monitoring and support. She reportedly regained her previous level of functioning over the next twelve months and returned to work.

Five years later, Mrs. E became pregnant; this planned pregnancy was uneventful. At this time, Mrs. E was no longer in psychiatric treatment or on psychotropic medications. She and her husband were educated by her psychiatrist, whom they contacted during her pregnancy, about the risk of another postpartum episode and particular affective and thought disorder symptoms to be monitored. Mrs. E's psychiatrist visited her in the hospital in the immediate postpartum period and made a home visit during postpartum week number two. No medications were given; Mrs. E continued to remain free of symptoms.

\section{DISCUSSION}

Women who experience episodes of postpartum psychosis are at increased risk for subsequent psychiatric illness regardless of the diagnosis received at the time of 
initial illness (10). For women without prior psychiatric history, the relatively abrupt onset of symptoms, the severity of the illness, and the associated isolation and guilt, make contemplation of further pregnancy an understandably difficult and complex process. Often the women and their families bring their concerns to their obstetricians and to the psychiatrists previously involved in their treatment with specific questions regarding chances of recurrent psychiatric illness. The risks involved in becoming pregnant again for any woman with a history of postpartum psychosis are great, including possible recurrence of psychotic symptoms, rehospitalization, estrangement from family members and disruption in work. It is noteworthy that at least one study has documented that women who suffer from puerperal psychosis are not generally discouraged by their experience and have more children at a rate similar to controls (11).

Long term follow-up study of women whose puerperal psychosis was their first psychiatric illness, such as the cases described, indicates that $38 \%$ who had subsequent pregnancies experienced another postpartum illness, defined as requiring hospitalization, or adequately documented outpatient treatment and medication. In this same group, $28 \%$ of subsequent pregnancies resulted in frank postpartum psychosis (10). Therefore, psychiatrists treating this population can advise women of the approximately 7 in 10 chance of an uneventful delivery and postpartum period.

In the three cases reviewed, women without prior psychiatric history experienced postpartum psychosis requiring inpatient hospitalization. The three cases are illustrative in that all three women without prior psychiatric histories became significantly impaired, yet were responsive to aggressive treatment. In all three cases, they were able to return to their previous highest level of functioning eventually requiring neither medication nor outpatient psychiatric treatment. When these women became pregnant again, they consulted their previously treating psychiatrists who followed them through pregnancy, delivery and the postpartum period.

At present, there are no indications for prophylactic pharmacologic intervention in the asymptomatic women at high risk; while lithium use has been proposed (20), no double-blind, placebo-controlled study using lithium in the immediate postpartum period has been done. The McNeil $(17,18,19)$ studies of mental health characteristics of mothers during pregnancy, life situation and the experience of pregnancy, and psychosocial aspects of labor and delivery, together do not clearly point to a psychosocial profile which puts women at risk for postpartum psychosis. There is no evidence that manipulation of psychosocial stressors will lessen the risk for further puerperal episodes. Therefore, patient education, alertness to early signs of psychosis, and aggressive intervention, if indicated, are at present the cornerstones of treatment.

\section{REFERENCES}

1. Miller LJ: Postpartum psychosis. Current Opinion in Psychiatry 3:62-65, 1990

2. Gitlin MJ, Pasnau RO: Psychiatric syndromes linked to reproductive function in women: A review of current knowledge. Am J Psychiatry 148:1413-1422, 1989

3. American Psychiatric Association: Diagnostic and statistical manual of mental disorders, ed 3, revised. Washington, DC American Psychiatric Association 1987 
4. Brockington IF, Winokur G, Dean C: Puerperal psychosis. In Brockington IF, Kumar R (eds): Motherhood and mental illness. London, Academic Press, Chapter 3, 1982

5. Hamilton JA: Postpartum psychiatric syndromes. Psychiatric clinics of North America 12:89-103, 1989

6. Kendell RE, Chalmers JC, Platz L: Epidemiology of puerperal psychosis. Br J Psychiatry 150:662-673, 1987

7. Dean C, Kendell RE: The symptomatology of puerperal illness. Brit J Psychiatry 139:128133,1981

8. Meltzer ES, Kumar R: Puerperal mental illness clinical features and classification: A study of 142 mother-and-baby admissions. Brit J Psychiatry 147:647-654, 1985

9. Brockington IF, Cernik KF, Schofield EM, Dawning AR, Francis AF, Keelan C: Puerperal psychosis: Phenomena and diagnosis. Arch Gen Psychiatry 38:829-833, 1981

10. Davidson J, Robertson E: A follow-up study of postpartum illness, 1946-1978. Acta Psychiatr Scand 71:451-457, 1985

11. Protheroe C: Puerperal psychoses: A long term study 1927-1961. Brit J Psychiatry 115:9-30, 1969

12. Reich T, Winokur G: Postpartum psychoses in patients with manic depressive disease. J Nerve Ment Dis 151:606-68, 1970

13. Mallett P, Marshall EJ, Blacker CVR: Puerperal psychosis following male-to-female sex reassignment. Brit J Psychiatry 155:257-259, 1989

14. Stewart DE, Addison AM, Robinson GE, Joffe R, Burrow GN, Olmstead MP: Thyroid function in psychosis following childbirth. Am J Psychiatry 145:1579-1581, 1988

15. Riley D, Watt D: Hypercalcemia in the etiology of puerperal psychosis. Biological Psychiatry 20:479-488, 1985

16. Kendell RE, Rennie D, Clarke JA, Dean C: The social and obstetric correlates of psychiatric admission in the puerperium. Psychol Med 11:341-350, 1981

17. McNeil TF: A prospective study of postpartum psychoses in a high risk group 3. Relationship to mental health characteristics during pregnancy. Acta Psychiatr Scand 77:604-610, 1988

18. McNeil TF: A prospective study of postpartum psychosis in a high risk group 4. Relationship to life situation and experience of pregnancy. Acta Psychiatr Scand 77:645-653, 1988

19. McNeil TF, A prospective study of postpartum psychosis in a high risk group 5 . Relationship to psychosocial aspects of labor and delivery. Acta Psychiatr Scand 78:471-477, 1988

20. Stewart DE: Prophylactic lithium in postpartum affective psychosis. J Nerve Ment Dis $176: 485-489,1988$ 